\title{
Influence of heat flux loading patterns on the surface cracking features of tungsten armor under ELM-like thermal shocks
}

\author{
Muyuan $\mathrm{Li}^{\mathrm{a}}$, Ewald Werner ${ }^{\mathrm{a}}$, Jeong-Ha You ${ }^{\mathrm{b}, *}$ \\ ${ }^{a}$ Lehrstuhl für Werkstoffkunde und Werkstoffmechanik, Technische Universität München, Boltzmannstr.15, 85748 Garching, Germany \\ ${ }^{b}$ Max-Planck-Institut für Plasmaphysik, Boltzmannstr.2, 85748 Garching, Germany
}

\begin{abstract}
In this work, the influence of different high heat flux (HHF) loading patterns on the surface cracking of tungsten was investigated under edge-localized mode (ELM)-like thermal loads. Two numerical approaches were employed, namely, the extended finite element method (XFEM) and the virtual crack tip extension (VCE) method. Comparative assessment of initial cracking and crack growth was conducted for six HHF loading patterns (combinations of three spatial and two temporal variants) assuming the same deposited energy for all cases. A ramp pulse with a longer duration leads to slightly lower temperatures and stresses in comparison to a constant pulse with a shorter duration, and no significant difference in cracking appears for these two temporal loading scenarios. In the central part of the loading area, cracks propagate perpendicularly to the surface and the final length of these cracks is dependent on the applied power density. For both triangular and uniformly distributed HHF loadings, cracks initiated near the position, where the peak stress occurred at the surface, tend to kink from the initial vertical paths and then grow parallel to the surface. The driving force for this type of crack propagation is larger under uniform than triangular loading.
\end{abstract}

Keywords: extended finite element method, $J$-integral, ELM-like thermal shock

\section{Introduction}

The plasma-facing components (PFCs), such as divertor and first wall, of a thermonuclear reactor will be subjected to harsh operational environment due to the interaction with burning fusion plasma. One of the most prominent loading features for the PFCs is the high heat flux (HHF) generated as a consequence of intense bombardment of energetic particles, radiation and neutron wall loading [1]. For instance, the ITER divertor is supposed to withstand a steady state heat flux load of $10 \mathrm{MW} / \mathrm{m}^{2}$ during normal operation and a slow transient heat load of up to $20 \mathrm{MW} / \mathrm{m}^{2}$ for $10 \mathrm{~s}[1,2]$. Furthermore, transient events are expected that are triggered by plasma instability such as edge-localized modes (ELMs).

Since high energy confinement with high pressure is essentially required for ITER and DEMO reactors, PFCs have to withstand transient thermal loads induced by ELMs resulting from this circumstance. Therefore, ELMs are attracting increasing attention. ELMs stand for repetitive bursts of the edge plasma triggered by magnetohydrodynamics (MHD) [3]. A large ELM event causes violent expulsion of heat and particles that are directed onto the divertor target. In ITER, the maximum energy density to be deposited on the divertor target (inner plate) by an ELM is expected to reach $0.5 \mathrm{MJ} / \mathrm{m}^{2}$ (controlled) or $10 \mathrm{MJ} / \mathrm{m}^{2}$ (uncontrolled) where the pulse duration time is 0.25 and $0.5 \mathrm{~ms}$, respectively, and the frequency ranges between $20-40 \mathrm{~Hz}$ for the controlled and $1-2 \mathrm{~Hz}$ for the uncontrolled mode [1].

\footnotetext{
${ }^{*}$ Corresponding author. Tel.: +49 0893299 1373; fax:+49 08932991212.

Email address: you@ipp.mpg.de (Jeong-Ha You)
} 
Due to the large amount of thermal energy expelled in a short time and the large number of occurrence, ELM events pose a particularly critical loading situation for PFCs [4]. In ITER and DEMO reactors the divertor target will be cladded with protection armor. Currently, tungsten is considered the most promising armor material due to its favorable properties [1, 5-7]. Since the tungsten armor has to withstand ELM loads for an extended period (several years), the damage and failure of tungsten caused by ELM-like thermal shock loads is a critical design concern.

In the literature there are ample experimental reports on the damage behavior of tungsten under simulated ELMlike HHF loads using various kinds of energy sources (electron, plasma, laser) $[4,8,9]$. These tests showed that significant damage can be formed under ELM-like HHF loads. The most dominant damage feature was surface cracking at lower temperatures whereas plastic deformation begins to prevail at temperatures above the ductile-tobrittle transition temperature (DBTT). Under excessive heat flux surface melting takes place followed by rapid resolidification. The re-solidified layer is prone to cracking. The development of damage turned out to depend on temperature, microstructure, material grade and the type of energy source employed [10-13].

The cracking behavior of HHF-heated tungsten is governed by the unbalance between the thermal stress intensity near the surface and the fracture toughness which is a material parameter. The former stands for the driving force for cracking while the latter is a measure for the resistance of the material against cracking. Both quantities are dependent on local temperature. Under ELM-like HHF loads the surface layer undergoes fast transient fluctuations of temperature and stress. The high temperature peak leads to transient thermal softening and compressive plastic flow of the surface layer. Recently, the present authors reported that the local plastic flow induces significant tensile residual stress upon cooling and that this tensile stress is responsible for surface cracking [14]. Furthermore, they could explain the impact of applied power density and the effect of base temperature on cracking in accordance with experimental observations.

In real HHF experiments or actual divertor operation, the pulse of a heat flux load can have different temporal and/or spatial profiles for a given energy deposition. However, since it is still unclear how the HHF loading pattern affects cracking under ELM-like loading conditions, our study is devoted to this topic. For this purpose, we employ the finite element method (FEM) together with computational fracture mechanics tools. Two different theoretical approaches of fracture mechanics are applied: the extended FEM (XFEM) and the virtual crack extension (VCE) method. Three different spatial profiles of energy distribution and two different temporal scenarios are considered while keeping the total deposited energy constant. Comparative predictions on the initial cracking patterns and crack growth behavior are presented and their implications are discussed.

\section{FE model}

\subsection{Model geometry}

The finite element (FE) model was built according to typical settings realized in thermal shock experiments at Forschungszentrum Jülich. Tungsten samples with dimensions of $12 \mathrm{~mm} \times 12 \mathrm{~mm} \times 5 \mathrm{~mm}$ were mounted on a heated sample holder, so that the base temperature of the samples could be adjusted between room temperature and $800{ }^{\circ} \mathrm{C}$. A nearly homogeneous heat flux load was achieved in a square of $4 \times 4 \mathrm{~mm}^{2}$ at the top surface of the sample by fast scanning of the surface with and electron beam. In the FE model, a disk shaped sample was considered instead of the real dimensions of the tungsten sample (see Fig. 1 a). The area of the top surface and the height of the disk model

were the same as those of the tungsten sample. The loading area was assumed to be a circle with an area of $16 \mathrm{~mm}^{2}$ instead of a square. As a consequence of these simplifications, a two-dimensional axisymmetric model could be set up for the right half of the vertical cross section considering the rotational symmetry of the model geometry, see Fig. 1 b. The advantage of the simplified model is that one can save computational efforts by reducing the dimension of the FE model, and one can avoid convergence problems possibly encountered in three-dimensional fracture mechanics 
simulations. The simulation tool for the computation was the commercial FEM code ABAQUS [15]. The finite element used in the simulations was a four-node axisymmetric quadrilateral element. To avoid mesh sensitive results, it is necessary to build a sufficiently fine mesh in the vicinity of the region of heat flux loading. There, the element edge size was $20 \mu \mathrm{m}$ (see Fig. $1 \mathrm{c}$ ).

\subsection{Materials}

The numerical simulations in this work were performed in a continuum mechanics framework, and the material was assumed to be homogenous and isotropic for simplicity. It should be noted that industrially manufactured tungsten products often show significant anisotropy in fracture stress and fracture toughness due to strongly textured microstructure produced by rolling. Isotropic fracture toughness property may be achieved by specific production methods such as powder injection molding. Thermal material parameters of tungsten, such as thermal conductivity, coefficient of thermal expansion and specific heat, as well as mechanical material parameters, such as Young's modulus and yield stress, refer to the data presented in literature [16, 17]. Thermal and mechanical material parameters of tungsten at selected temperatures are listed in Tables 1 and 2.

Table 1. Thermal material parameters of tungsten at selected temperatures [16]

\begin{tabular}{ccccc}
\hline \hline $\begin{array}{c}\text { Temperature } \\
\left({ }^{\circ} \mathrm{C}\right)\end{array}$ & $\begin{array}{c}\text { Thermal conductivity } \\
(\mathrm{W} / \mathrm{mK})\end{array}$ & $\begin{array}{c}\text { Density } \\
\left(\mathrm{kg} / \mathrm{m}^{3}\right)\end{array}$ & $\begin{array}{c}\text { Specific heat } \\
(\mathrm{J} / \mathrm{kgK})\end{array}$ & $\begin{array}{c}\text { Coefficient of thermal expansion } \\
\left(10^{-6} / \mathrm{K}\right)\end{array}$ \\
\hline 27 & 176 & 19299 & 133 & 4.74 \\
927 & 114 & 19051 & 155 & 5.06 \\
1927 & 99 & 18725 & 180 & 6.77 \\
2727 & 92 & 18379 & 218 & 9.19 \\
\hline
\end{tabular}

Table 2. Mechanical material parameters of tungsten at selected temperatures [17]

\begin{tabular}{ccc}
\hline \hline Temperature $\left({ }^{\circ} \mathrm{C}\right)$ & Young's modulus $(\mathrm{GPa})$ & Yield stress $(\mathrm{MPa})$ \\
\hline 20 & 399 & infinite $^{a}$ \\
200 & 391 & 1221 \\
600 & 375 & 724 \\
1000 & 356 & 467 \\
1600 & 321 & 64 \\
2000 & 278 & 42 \\
\hline
\end{tabular}

${ }^{a}$ No value is reported in [17]. Here, it is assumed that tungsten behaves purely elastic at this temperature.

The values of yield stress and ultimate tensile strength of tungsten are nearly identical at the same temperature [17]. Therefore, tungsten is assumed to behave elastic-ideally plastic in the simulations conducted in this work. It should be noted that the elongation of tungsten at fracture increases significantly with increasing temperature [18].

\subsection{Loading patterns}

Six HHF loading patterns are considered as combinations of three spatial profiles and two different temporal scenarios. The three spatial profiles are uniform, a triangle with a steep slope and a triangle with a gradual slope (see Fig. 2). The triangular energy distribution is used as a rough estimate of a Gaussian profile, which is the typical energy distribution on the target material for a static electron beam. The power density of the uniform loading, $F$, is $0.8 \mathrm{GW} / \mathrm{m}^{2}$. The two temporal scenarios are either a constant or a ramp loading (see Fig. 3). For the constant loading, the power density is constant throughout the loading time, while for the ramp loading, the power density starts from 
zero and keeps increasing to the same power density of the constant loading at the end of the loading time. When the power is turned off, the power density is assumed to be reduced to zero immediately for both temporal scenarios. The duration of the constant loading is $1 \mathrm{~ms}$, and the duration of the ramp loading is $2 \mathrm{~ms}$. The base temperature is $20{ }^{\circ} \mathrm{C}$. All six HHF loading patterns employ the same total energy input within the corresponding loading time.

\section{Thermal simulations}

Fig. 4 shows the surface temperature for different loadings at the end of heating. The surface temperature profile is similar to the energy distribution at the surface, which indicates that the surface temperature is proportional to the power density. The triangular loading with a steep slope generates the largest peak temperature at the surface in comparison to the other two energy distributions. In general, the surface temperature for the ramp loading scenario is slightly smaller than what is predicted for the constant loading. This is due to the fact that the ramp loading entails longer loading times, so more energy is dissipated into the bulk material during heating. The difference in peak temperature between the constant and the ramp loading scenarios is the largest for the triangular loading with a steep slope. With this energy distribution, the peak temperature is $3142{ }^{\circ} \mathrm{C}$ for the ramp loading scenario, while the peak temperature for the constant loading scenario is $3371{ }^{\circ} \mathrm{C}$. The difference is reduced with decreasing power density. For the triangular loading with a gradual slope or the uniform loading, the difference of the peak temperatures is less than $100{ }^{\circ} \mathrm{C}$ between the constant and the ramp loading scenarios.

\section{Mechanical simulations}

In Fig. 5, surface plastic strain in radial direction is shown at the end of heating. The distribution of plastic strains at the surface is similar to the corresponding energy distribution. The maximum magnitude of plastic strain in radial direction for the triangular loading with a steep slope is approximately four times that for the uniform loading and the triangular loading with a gradual slope, while the peak temperature is only about two times as high, see Fig. 4. This is because the coefficient of thermal expansion is larger at a higher temperature. Thus, larger plastic deformation is generated for the same temperature increase at a higher temperature.

Fig. 6 shows the surface plastic strain in radial direction at the end of cooling. The magnitudes of plastic strains for different loadings are reduced to a similar level in the central part of loading area during cooling.

In Fig. 7, surface stress in radial direction is shown at the end of cooling. For all six cases, the distributions of the surface stresses in radial direction are also similar, alike to the plastic strains. The peak stress in radial direction appears 1.5 to $2.3 \mathrm{~mm}$ away from the center of the loading area depending on the energy distribution. The triangular loading with a steep slope results in the largest peak stress in radial direction of all energy distributions. At the center of the loading area, the stress in radial direction is slightly larger for the triangular loading with a gradual slope than for the other two energy distributions. For ramp loading scenarios, the peak stress in radial direction of the triangular loadings occurs closer to the center of the loading area than for the constant loading scenarios. Fig. 8 shows the stress in radial direction at a depth of $0.2 \mathrm{~mm}$ at the end of cooling. Although the stresses in radial direction for the six HHF loading patterns are all tensile and similar at the surface, the stress in radial direction for the triangular loading with a steep slope is much larger than for loadings with the other two energy distributions at a depth of $0.2 \mathrm{~mm}$. For the triangular loading with a gradual slope, the stress is compressive at a depth of $0.2 \mathrm{~mm}$.

As for the thermal field, the difference of mechanical fields between the constant and the ramp loading scenarios is moderate. If strain rate dependent yield stress is considered in the calculation, the results may be influenced. However, considering that the difference of the loading duration and the similarity of the plastic strain field at the end of heating,

the strain rate for the constant scenarios is roughly twice the strain rate for the ramp loading scenarios, which indicates 
that the difference of the yield stress resulting from the difference of strain rate is negligible based on the data listed in literature [19].

\section{XFEM simulations}

Using the conventional finite element method, modeling stationary discontinuities requires boundary-conforming meshes for geometrically discontinuous domains, and the corresponding mesh refinement involves considerable computational efforts. However, XFEM alleviates the shortcomings associated with meshing crack surfaces.

XFEM was first introduced by Belytschko and Black [20]. It is an extension of the conventional finite element method based on the concept of so-called enrichment functions which enable modeling discontinuities such as cracks without any discrete mesh adaption.

To simulate crack initiation and propagation using XFEM, a maximum principal stress (MPS) criterion and an energy based damage evolution law are needed. Once the principal stress exceeds the maximum allowable value, a crack is initiated. At the same time, the cohesive stiffness in the elements, in which the crack formation occurs, is degraded. The degradation of cohesive stiffness is described by the energy based damage evolution law. If the energy dissipation associated with crack extension is larger than the fracture energy, the cohesive stiffness is zero, and the crack is completely opened. The value of ultimate tensile strength can in principle be used as an estimate for the MPS. The ultimate tensile strength of tungsten in the vicinity of DBTT $\left(400{ }^{\circ} \mathrm{C}-700^{\circ} \mathrm{C}\right)$ is about $900 \mathrm{MPa}-700 \mathrm{MPa}$ [17]. Considering that crack formation is mainly due to the brittleness of tungsten below DBTT, the MPS is defined to be $900 \mathrm{MPa}$. For the fracture energy in the course of damage evolution, $0.25 \mathrm{~mJ} / \mathrm{mm}^{2}$ is used, which is transferred from the fracture toughness obtained from the test performed at $400{ }^{\circ} \mathrm{C}$ by Gludovatz et al. [21] applying the concept of linear elastic fracture mechanics.

In Fig. 9, cracks are predicted by XFEM for different loadings. In these XFEM simulations, no precracks are defined, and multiple crack initiation is allowed. Cracking patterns resulting from the constant and the ramp loadings are similar, while the cracking patterns resulting from the uniform and the triangular loadings differ. For the uniform loading, there are many short cracks that appear in the loading area at the top surface and which propagate perpendicularly to the loading surface. Near the edge of the loading area, a crack is generated and which propagates parallel to the loading surface. For the triangular loading, cracks mainly propagate perpendicularly to the loading surface, while the cracks resulting from the triangular loading with a steep slope are much longer than those resulting from the triangular loading with a gradual slope.

The occurrence of multiple cracks can influence the initiation of other potential cracks by relaxing the stress concentration. In order to study a crack initiated at a specific position without any influence from other cracks, XFEM simulations were conducted with a single precrack, and no other crack initiation was allowed. As the constant and the ramp loading scenarios result in similar cracking patterns, only the constant loadings were studied here. Fig. 10 shows these results of the XFEM simulations with a single precrack at different positions for three energy distributions. In each simulation, a precrack of $40 \mu \mathrm{m}$ was assumed perpendicular to the loading surface. In the central part of the loading area, the precracks generally propagate perpendicularly to the loading surface for all three energy distributions. The crack length resulting from the triangular loading with a steep slope is the largest, due to the fact that its maximum power density is the largest. For the triangular loading with a steep slope and a precrack positioned $2.01 \mathrm{~mm}$ from the center of the loading area makes it propagate parallel to the loading surface i.e. deviate from its initial vertical path. A similar crack is found $2.23 \mathrm{~mm}$ away from the center of the loading area for the uniform loading. For the triangular loading with a gradual slope, the precrack $1.61 \mathrm{~mm}$ away from the center of the loading area tends to propagate towards the center of the loading area, but the driving force is not large enough for significant crack growth. 
As shown in Fig. 10, cracks are found near the position where the peak stress occurs for the uniform and triangular loadings with a steep slope (XFEM simulations with a single precrack). These cracks propagate parallel to the loading surface. However, the crack does not propagate parallel to the loading surface for the triangular loading with a steep slope, if multiple crack initiations are allowed, see Fig. 9. This is due to the stress relaxation resulting from the crack opening in the central part of the loading area. To confirm this conclusion, the XFEM simulations were made with two precracks at specific positions. One precrack was defined in the central part of the loading area $(d=0.81 \mathrm{~mm})$ while the other precrack was defined near the position where the peak stress occurs. The results of these calculations are shown in Fig. 11. Crack propagation parallel to the loading surface is hindered as a crack opening occurs in the central part of the loading area. This indicates that for power densities sufficiently large to induce cracking in the central part of the loading area, crack growth parallel to the loading surface will be impeded. If the power density is too small, no cracking will occur. For the aforementioned reasons the cracking pattern predicted for the uniform loading in Fig. 9 occurs within a certain range of the power density, which allows the occurrence of the cracks near the edge of the loading area but does not lead to serious cracking in the central part of the loading area. This cracking pattern should be avoided, since it may lead to an undesired concentration of thermal energy at the top surface and subsequent melting or erosion of surface material.

Compared to the triangular loading, the uniform loading is more likely to cause a crack near the position where the peak stress occurs and which will grow parallel to the loading surface. On one hand, the distance between the position of peak stress and the loading center is larger for the uniform loading than for the triangular loading, which indicates that the growth of cracks near the edge of the loading area is less influenced by cracking in the central part, see Fig. 11. On the other hand, the uniformly distributed stress field under the uniform loading can create many short cracks in the central part of the loading area at the same time, which reduces the driving force for a long crack, see Fig. 9. 
(a)
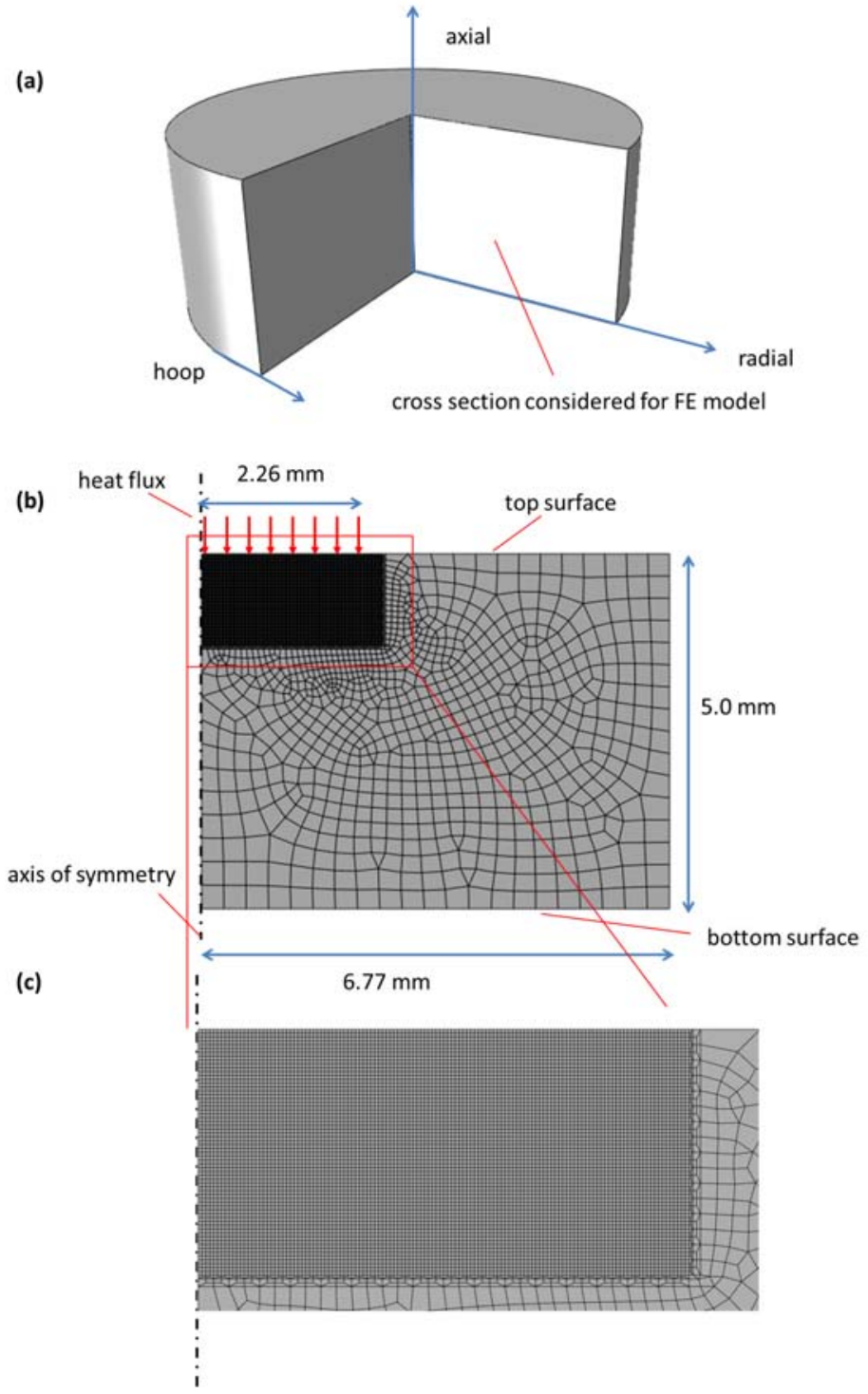

Fig. 1. (a) A schematic drawing of the model geometry, (b) two-dimensional FE model created for the right half of the vertical cross section. The mesh consists of axisymmetric elements reflecting the rotational symmetry of the model. The loading area is sketched for the uniform loading case, and the spatial profiles of power density for other loading scenarios are illustrated in Fig. 2 , (c) finer mesh in the vicinity of the region of heat flux loading. 


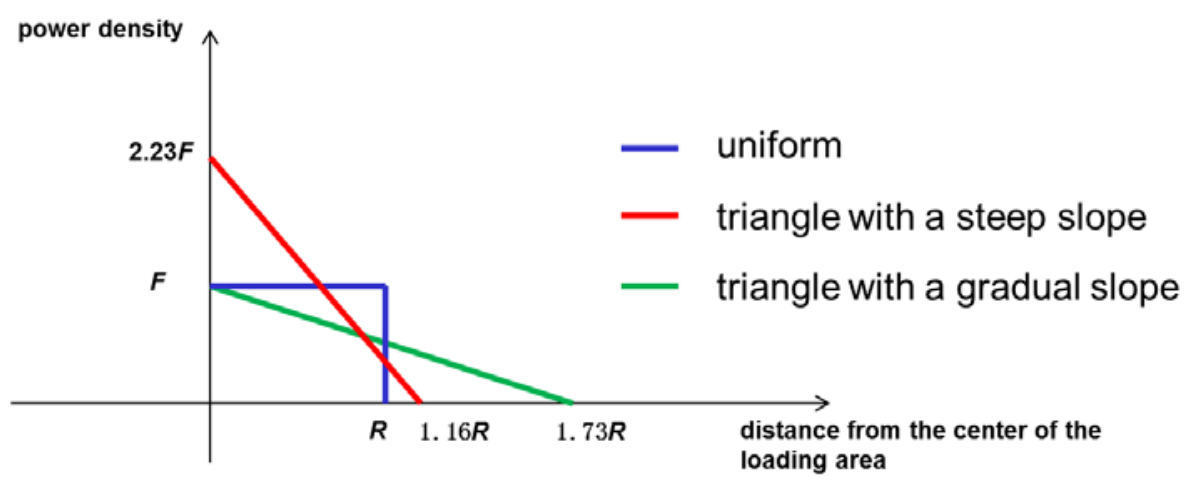

Fig. 2. Considered spatial profiles of the power density at the surface of the axisymmetric model, $F$ : power density for the uniform loading, $R$ : radius of the loading area for the uniform loading.

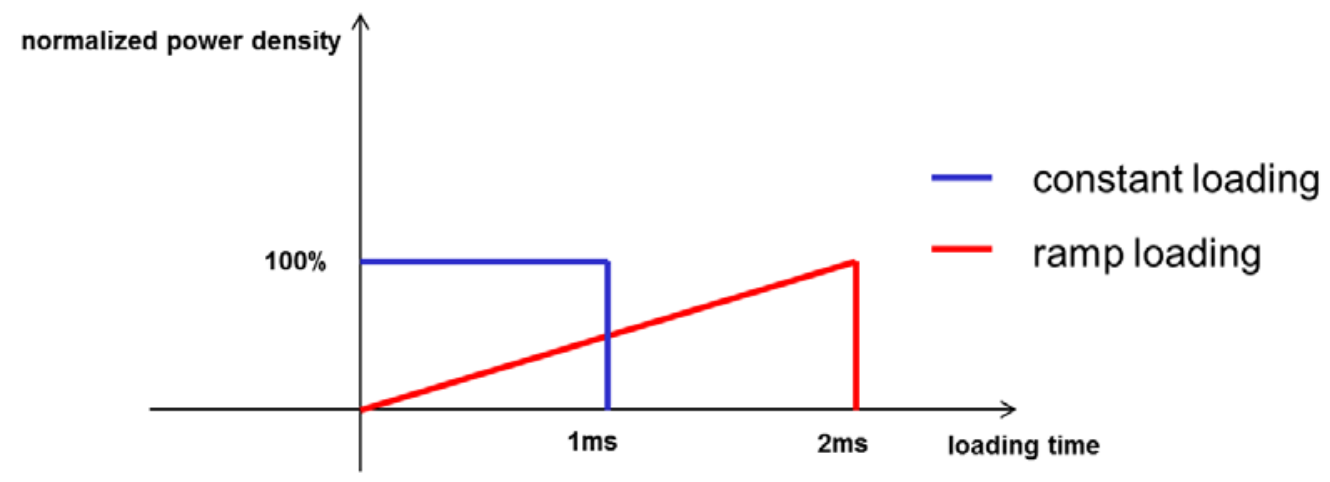

Fig. 3. Different temporal scenarios considered.
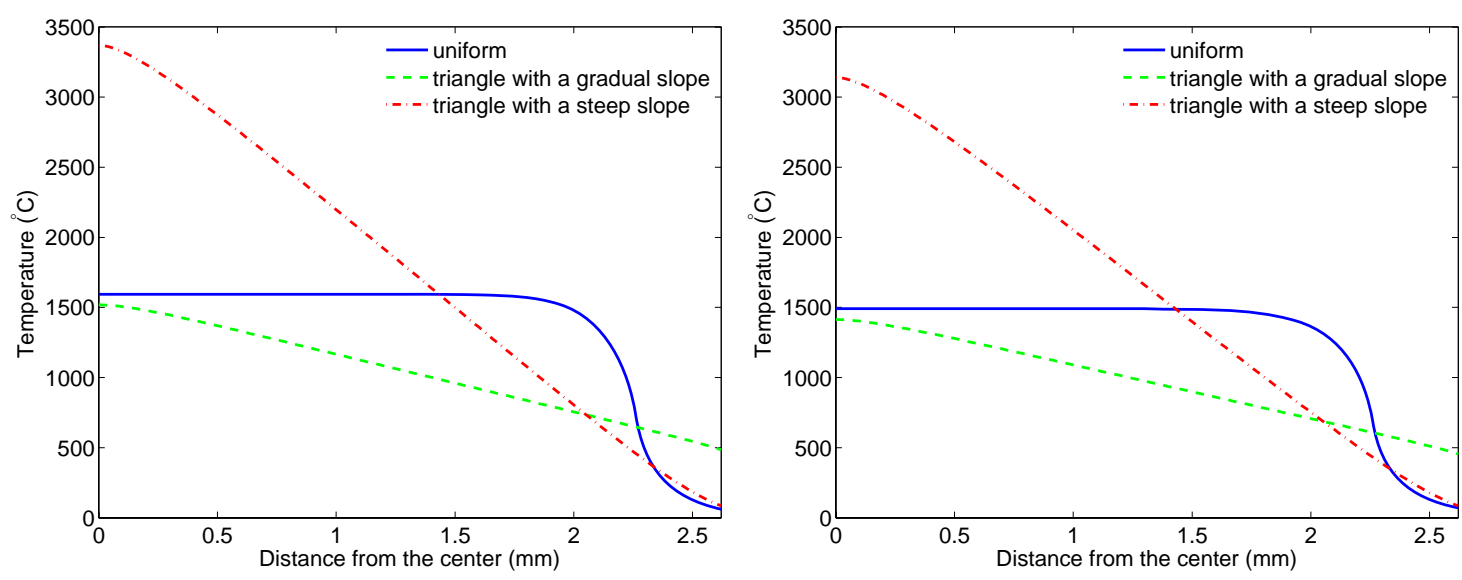

Fig. 4. Surface temperature at the end of heating for the constant (left) and ramp (right) loadings of three power density distributions. 

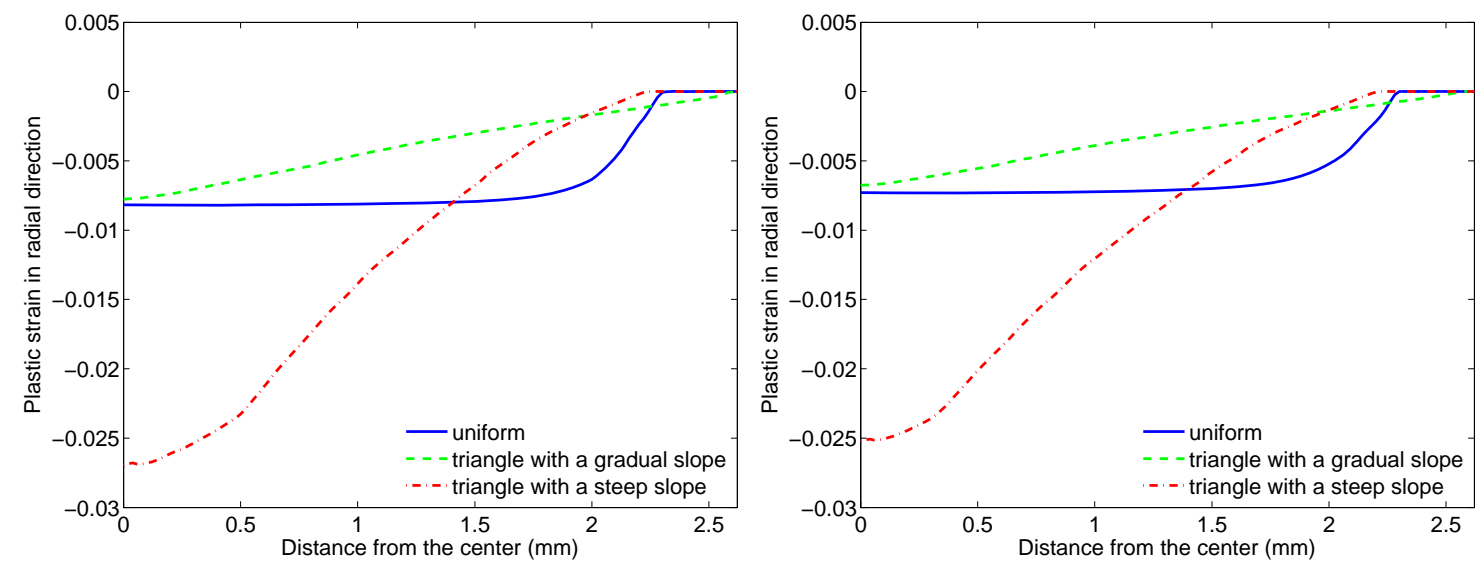

Fig. 5. Surface plastic strain in radial direction at the end of heating for the constant (left) and the ramp (right) loadings for three energy distributions.
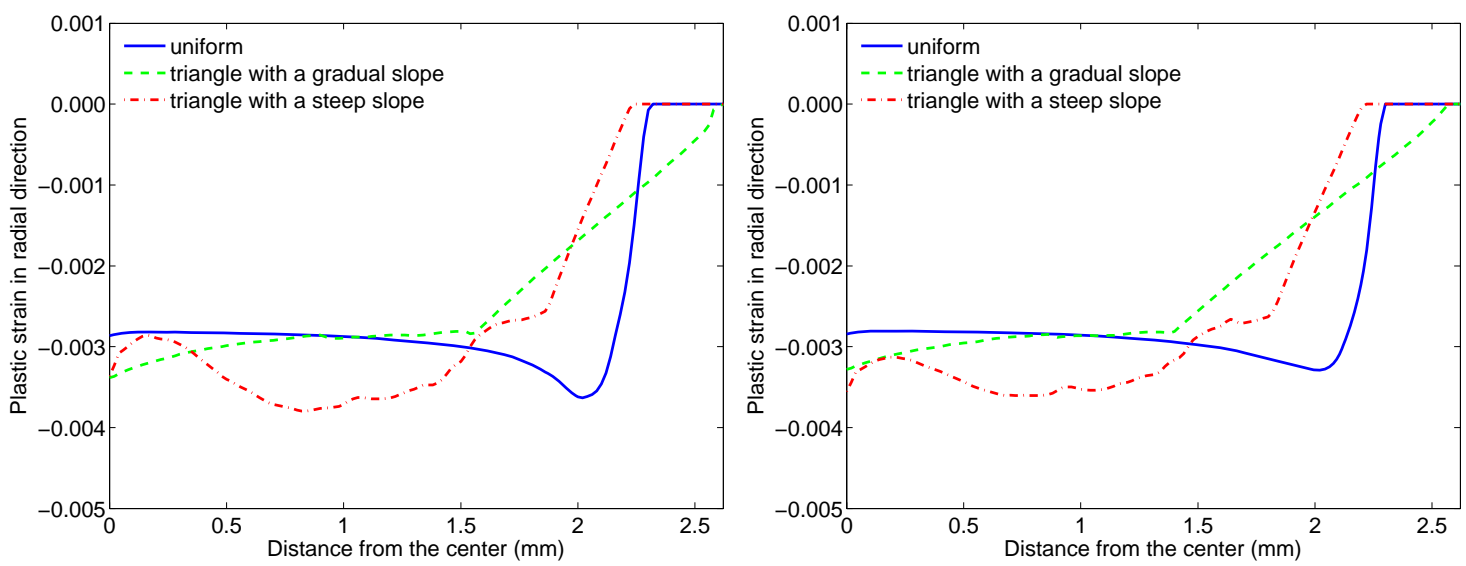

Fig. 6. Surface plastic strain in radial direction at the end of cooling for the constant (left) and the ramp (right) loadings for three energy distributions. 

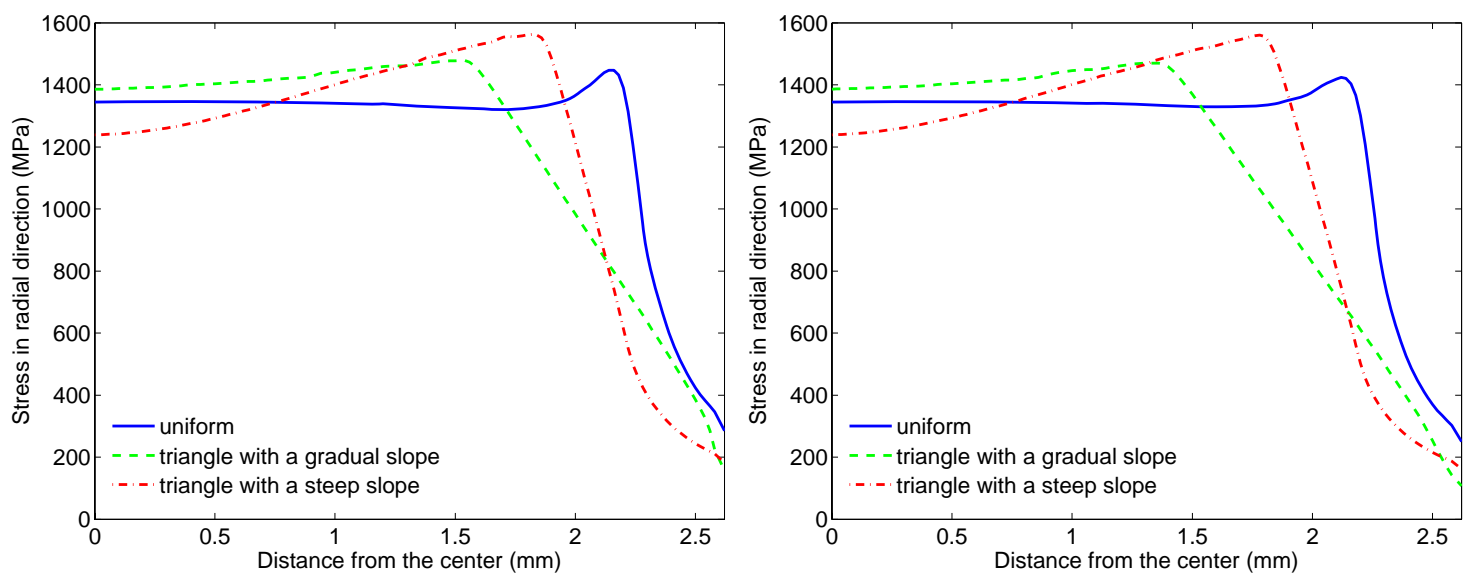

Fig. 7. Surface stress in radial direction at the end of cooling for the constant (left) and the ramp (right) loadings for three energy distributions.
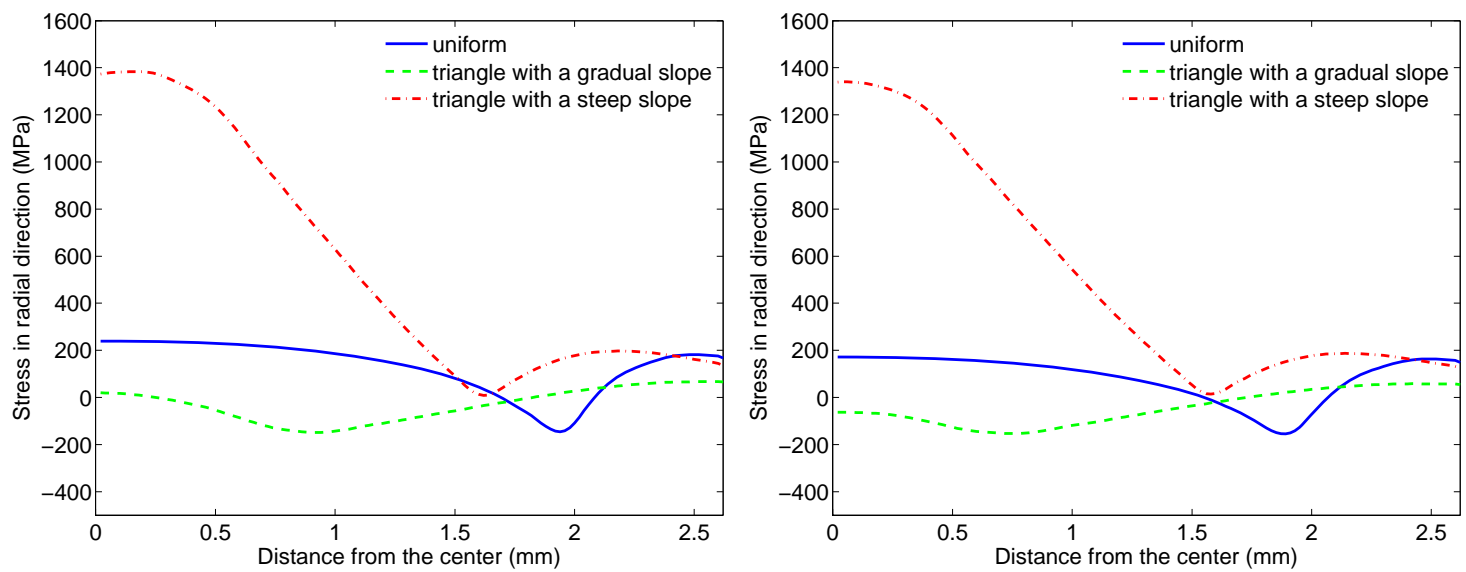

Fig. 8. Stress in radial direction at a depth of $0.2 \mathrm{~mm}$ at the end of cooling for the constant (left) and the ramp (right) loadings for three energy distributions. 

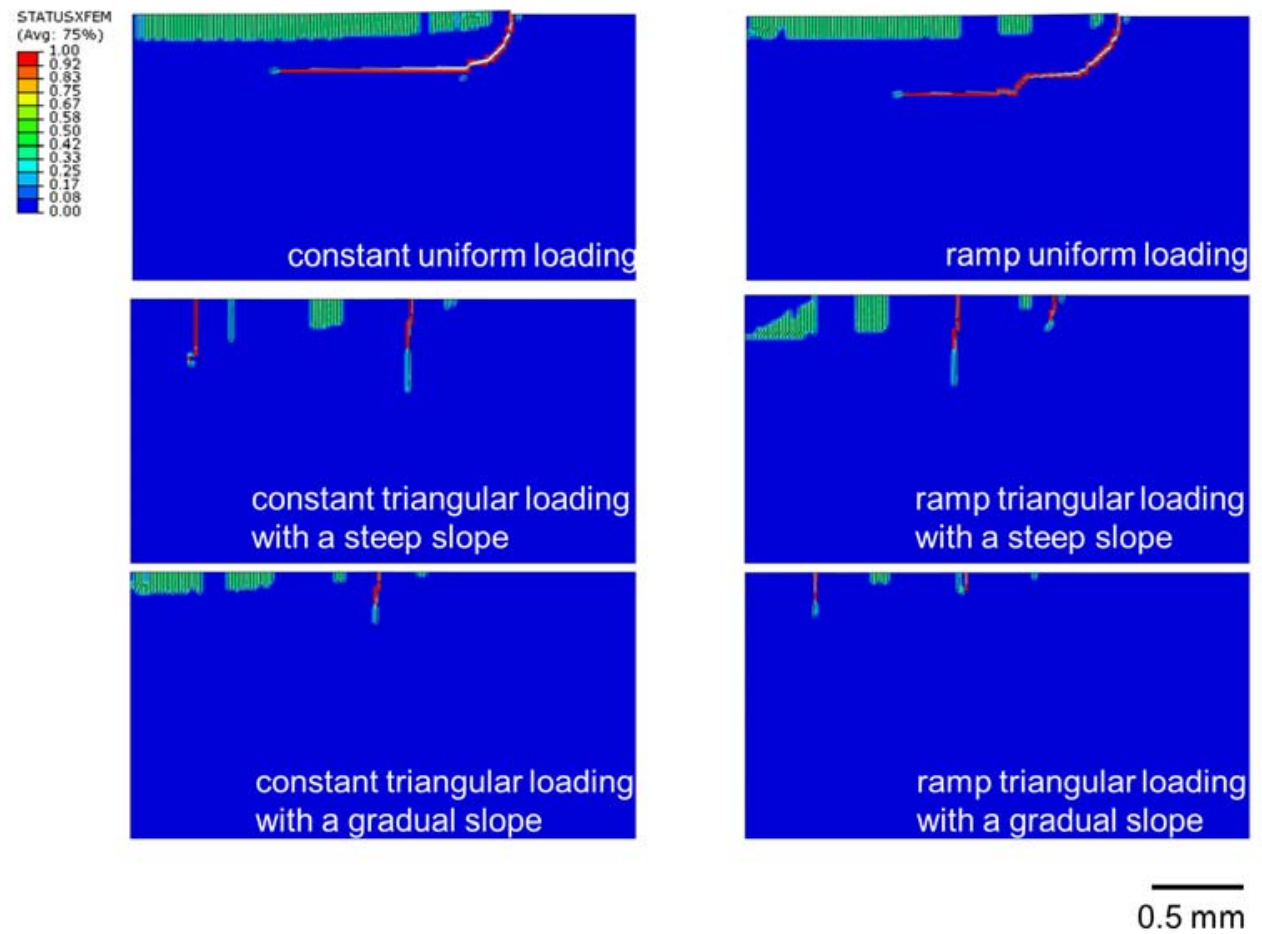

Fig. 9. Cracks predicted by XFEM without any precracks for six HHF loading patterns. The quantity STATUSXFEM characterizes damage evolution. A value of 1.0 characterizes an opened crack. Positive values smaller than 1.0 stand for cracks that require additional energy to be opened. 


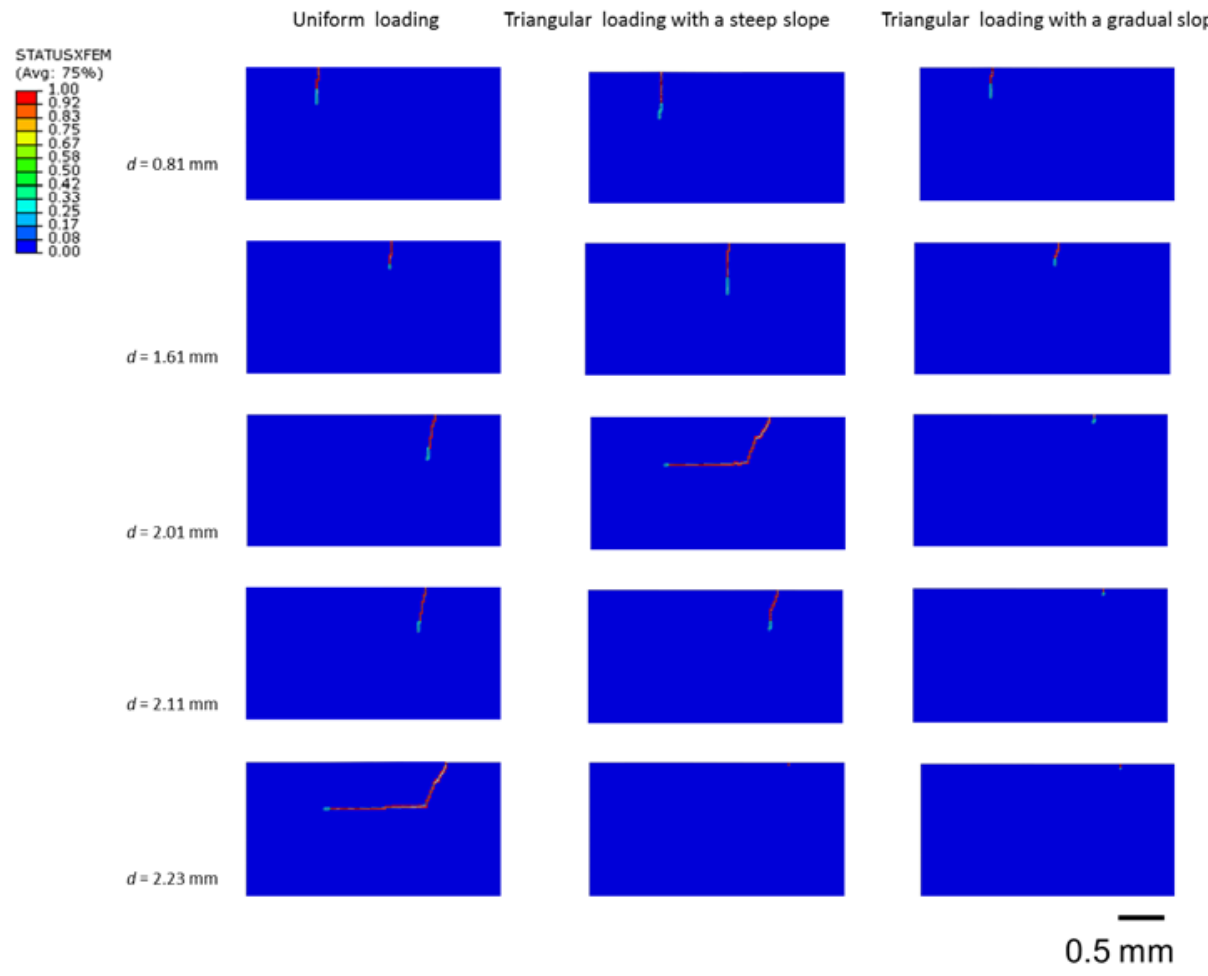

Fig. 10. Crack predicted by XFEM assuming a single precrack at different locations for three energy distributions.
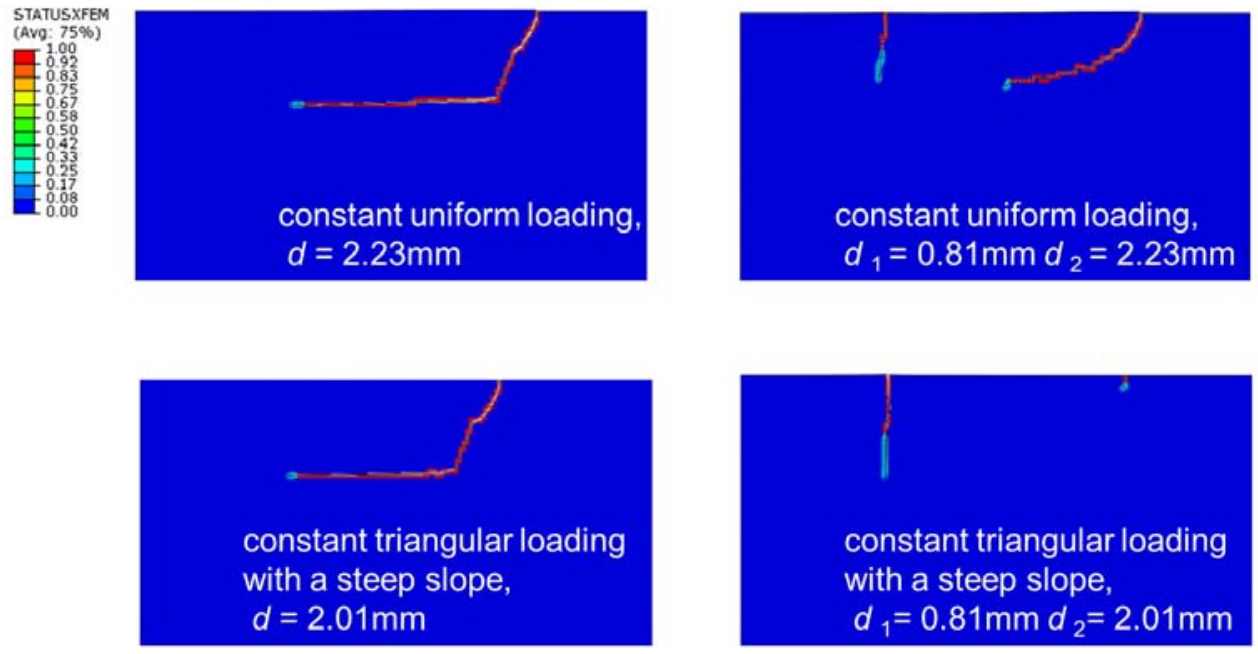

$\overline{0.5 \mathrm{~mm}}$

Fig. 11. Cracks predicted by XFEM with two precracks assumed. 


\section{6. $J$-integral}

The $J$-integral was first developed by Rice [22], and is a useful quantity for the analysis of the mechanical fields near crack tips. The $J$-integral is numerically attractive, since it can be evaluated by a path independent contour integral. To evaluate the contour integrals for computing $J$-integrals, the domain integral method is used, which is quite robust in the sense that accurate contour integral estimates are usually obtained even with quite coarse meshes. In this work, the $J$-integral is calculated using the FEM-based VCE method at the end of cooling, when the material behaves purely elastic. If plasticity occurs, $J$-integral calculation is also valid by describing the elasto-plastic material behavior as an "equivalent elastic material" in ABAQUS [15]. However, the residual stress influence must be considered, otherwise the $J$-integral will not be path-independent. In ABAQUS [15], the residual stress field can be treated as an initial strain field. A criterion for crack propagation is defined as follows: As the $J$-integral reaches its critical value $\left(J_{\mathrm{c}}\right)$, unstable fracture sets in and cracks can propagate. The critical value of the $J$-integral is defined to be the same as the fracture energy.

The $J$-integral is calculated for precracks of various lengths at different positions in order to compile a parametric study, see Fig. 12. In each calculation, a single precrack is defined with a fixed length. The critical value of the $J$-integral $\left(J_{\mathrm{c}}\right)$ is defined to be the same as the fracture energy used in the XFEM simulations. The direction of the virtual crack tip extension is downwards and perpendicular to the loading surface.

In Figs. 13, 14 and 15, $J$-integrals are shown for the six HHF loading patterns. In all six loading cases, the $J$ integrals for precracks in the central part of the loading area $(d=0.81 \mathrm{~mm})$ are larger than the critical value, which coincides with the XFEM prediction. The $J$-integrals for the ramp loading scenarios are slightly smaller than for the constant loading scenarios. For the triangular loading with a steep slope, the $J$-integrals for precracks in the central part of the loading area are much larger than for the uniform and the triangular loading with a gradual slope. The crack length of the longest precrack, for which the $J$-integral is larger than its critical value, is defined as the maximum crack length. The maximum crack length for the triangular loading with a steep slope is the largest (approx. $0.6 \mathrm{~mm}$ ), while the maximum crack length for the triangular loading with a gradual slope is less than $0.3 \mathrm{~mm}$. For the uniform loading and the triangular loading with a steep slope the $J$-integral for the precrack - which is $2.0 \mathrm{~mm}$ away from the center of the loading area - is larger than the critical value and thus a sufficient driving force is provided for crack propagation. For the triangular loading with a gradual slope, $J$-integrals for precracks $2.0 \mathrm{~mm}$ away from the center of the loading area are smaller than the critical value. This result coincides with the XFEM prediction that no crack growth occurs $2.0 \mathrm{~mm}$ away from the center of the loading area for the triangular loading with a gradual slope.

The most possible crack propagation direction is the direction in which the energy release rate is the largest. In Figs. 16, 17 and 18, the direction of the maximum energy release rate (indicated by the angle $\varphi$ in Fig. 12) of precracks of different lengths are shown for constant loadings with different energy distributions. In general, for a small crack length $(0.04 \mathrm{~mm})$, the angle is smaller than $10^{\circ}$. This is due to the fact that within the surface layer the tensile stress is much stronger than the shear stress. The angle increases as crack length increases. For the uniform loading, the angle increases significantly as the precrack is closer to the edge of the loading area. For the triangular loading with a steep slope, the maximum value of the angle occurs for a precrack about $2.0 \mathrm{~mm}$ away from the center of the loading area, where the crack propagates parallel to the loading surface (see the XFEM simulations in Fig. 10). For the triangular loading with a gradual slope, the energy release rate is smaller than its critical value, even though the angle of a crack of $0.32 \mathrm{~mm}$ length is about $40^{\circ}$, see Fig. 15 . As a result, no crack parallel to the loading surface can be found for the triangular loading with a gradual slope, while the crack near the position where the peak stress occurs does propagate parallel to the loading surface by kinking from its initial vertical path for the triangular loading with a steep slope and the uniform loading. This matches with the XFEM predictions shown in Fig. 10. However, it is should be noted that minor differences are to be expected between the direction of the maximum energy release rate calculated using the 


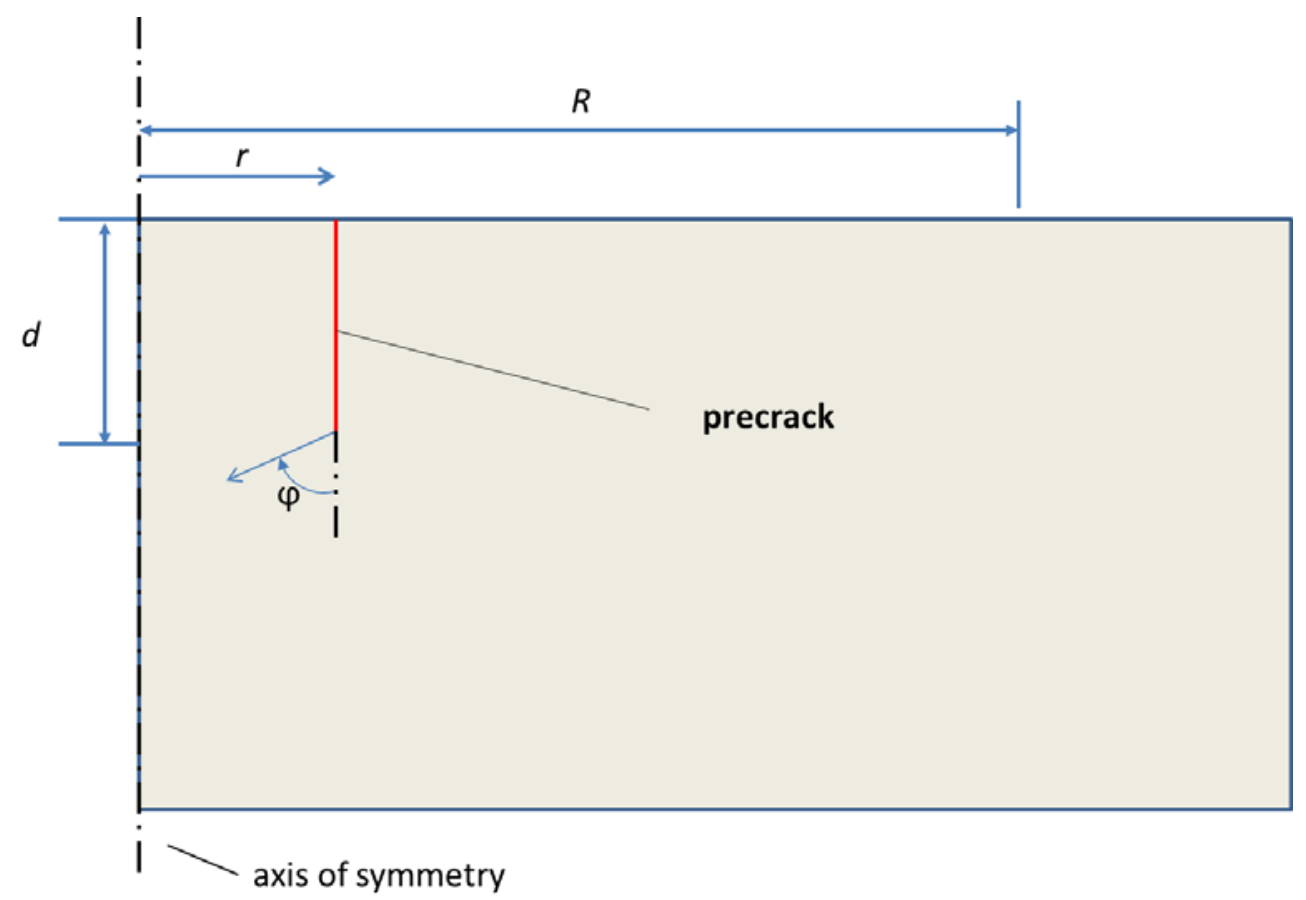

Fig. 12. Precrack definition for the $J$-integral calculation. $\varphi$ indicates the direction of the maximum energy release rate.

VCE method and the direction of crack propagation from the XFEM simulations. One reason is that the direction of the maximum release rate is calculated at the end of cooling, while the direction of crack propagation is calculated during the cooling (e.g. in the case of constant uniform loading, first cracks are initiated about 2 ms after shutdown of heat pulse where the temperature is reduced approximately down to $350{ }^{\circ} \mathrm{C}$.). 

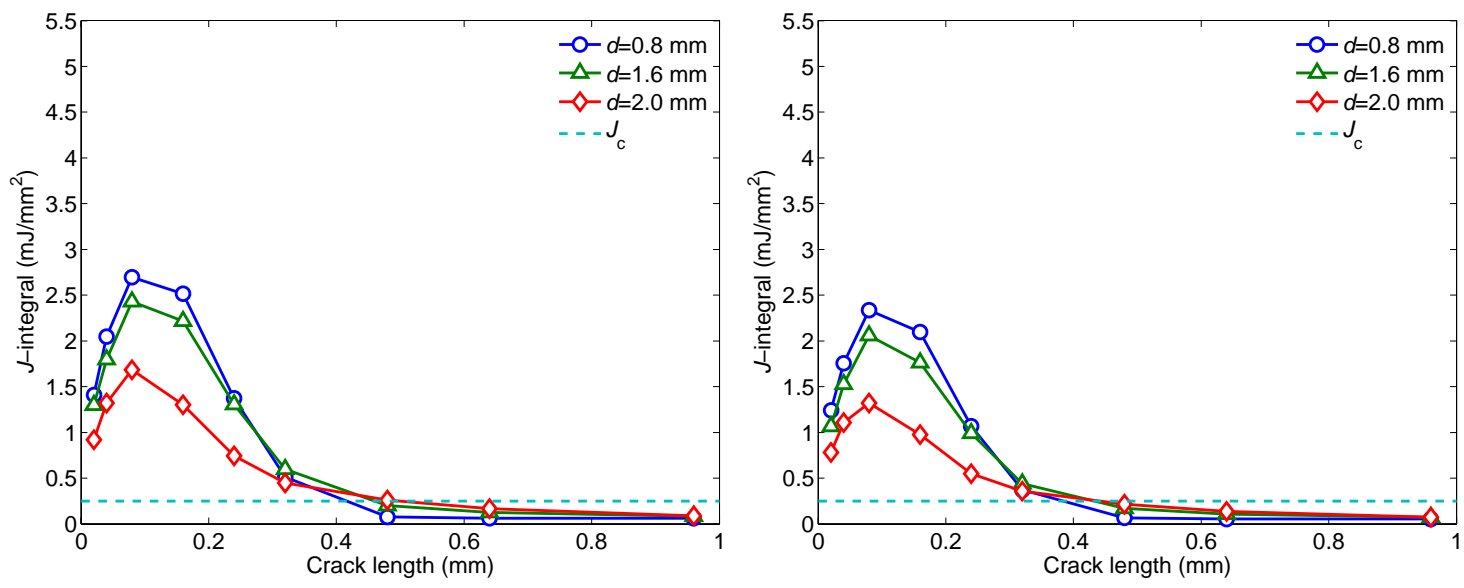

Fig. 13. $J$-integral for the constant (left) and the ramp (right) uniform loadings.
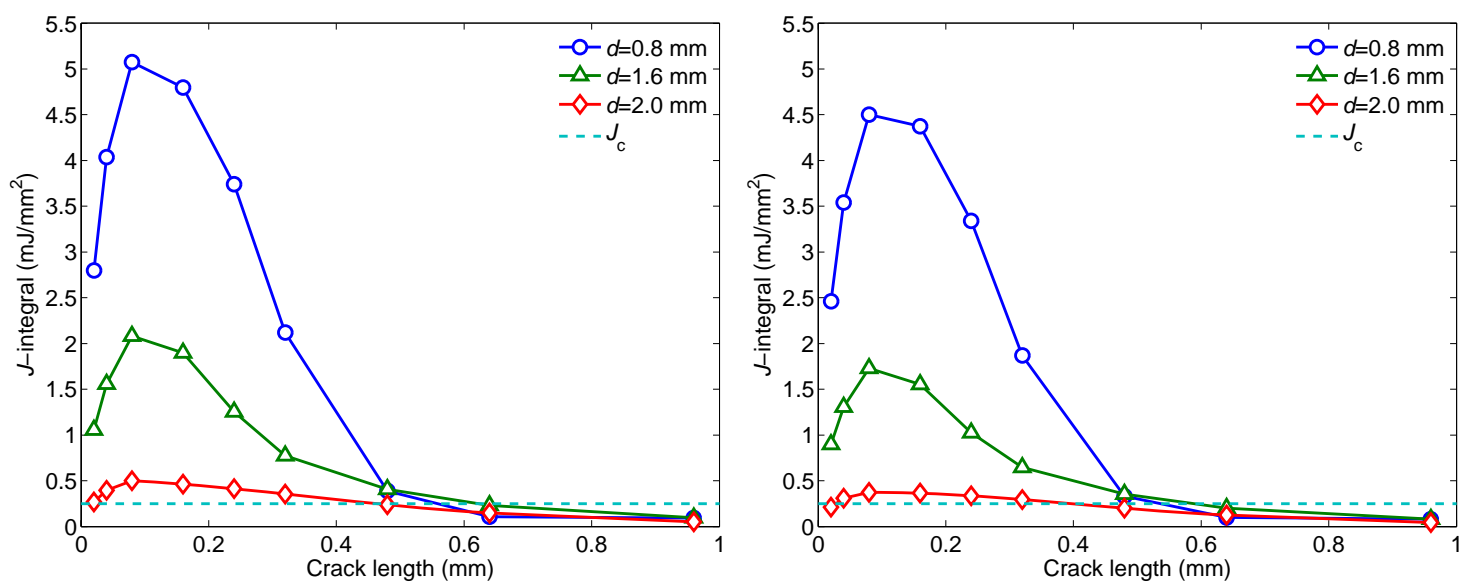

Fig. 14. $J$-integral for the constant (left) and the ramp triangular (right) loadings with a steep slope. 

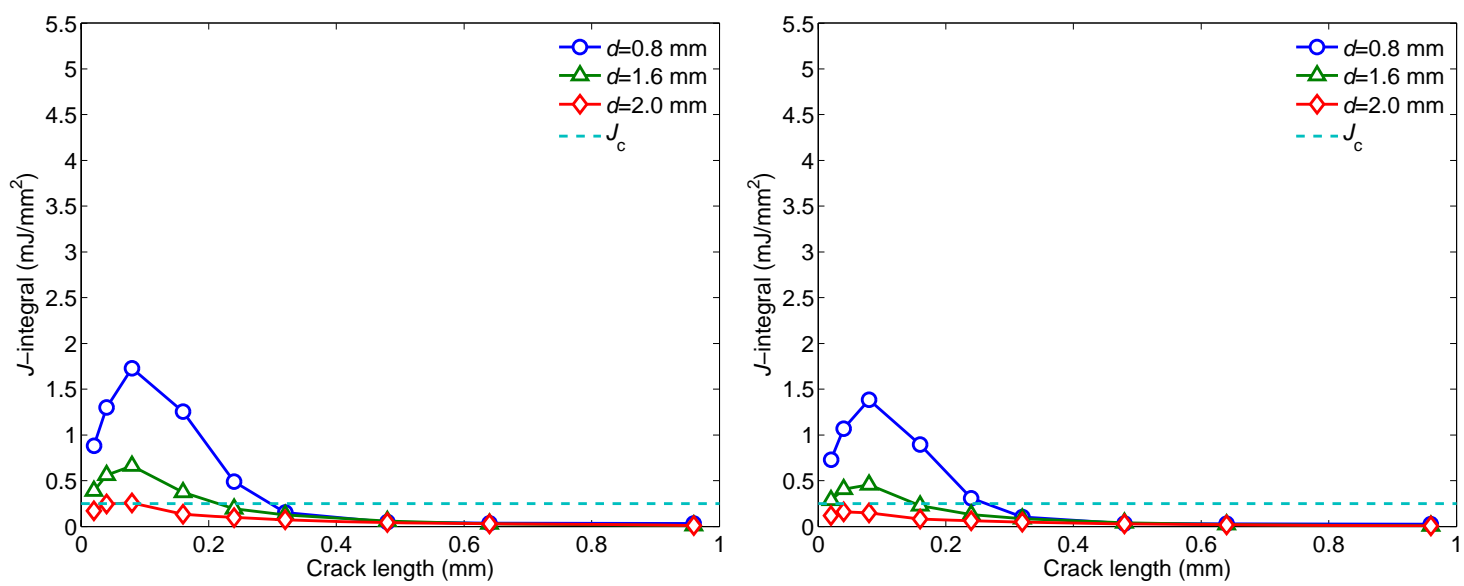

Fig. 15. $J$-integral for the constant (left) and the ramp triangular (right) loadings with a gradual slope.

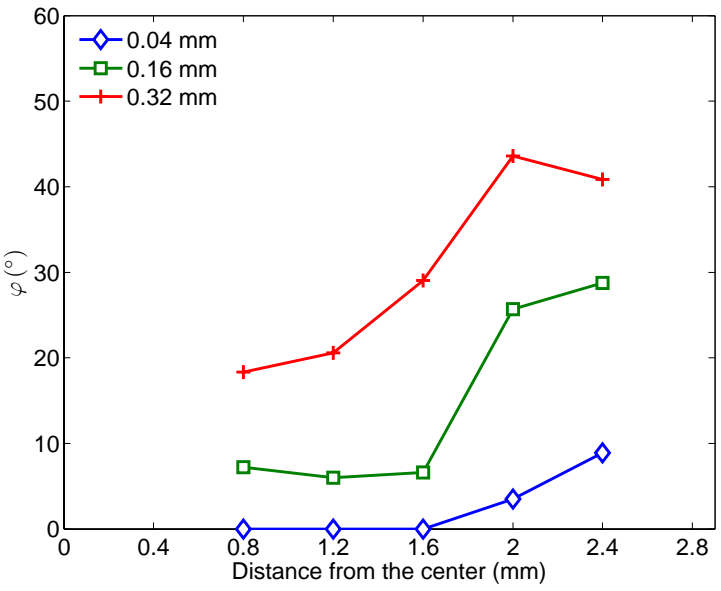

Fig. 16. Direction of the maximum energy release rate represented by angle $\varphi$ of precracks of different lengths for constant uniform loading. 


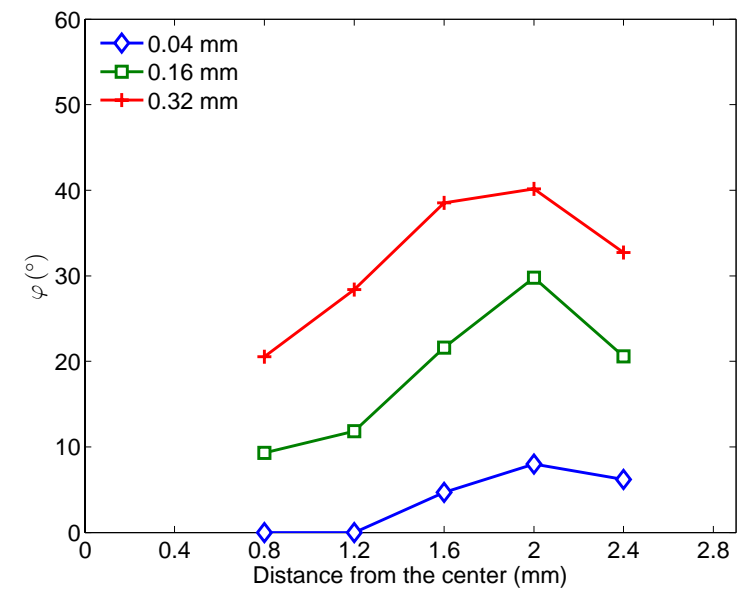

Fig. 17. Direction of the maximum energy release rate represented by angle $\varphi$ of precracks of different lengths for constant triangular loading with a steep slope.

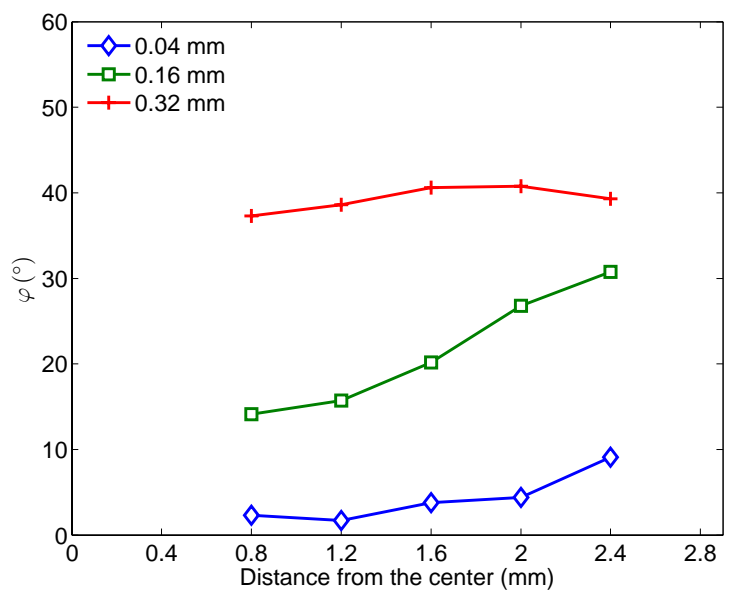

Fig. 18. Direction of the maximum energy release rate represented by angle $\varphi$ of precracks of different lengths for constant triangular loading with a gradual slope. 


\section{Summary}

In this study, the influence of different HHF loading patterns on the surface cracking of tungsten under ELM-like thermal loads was investigated by means of FEM-based fracture mechanics analysis with two different simulation tools. Comparative assessment of initial cracking and crack growth was conducted for six HHF loading patterns (combinations of three spatial and two temporal variants) assuming the same deposited energy for all cases. Several distinct effects were found as follows:

1. A ramp pulse with a longer duration leads to lower temperatures and stresses in comparison to a constant pulse with a shorter duration. Yet, the difference is rather moderate when both their maximum power density and total deposited energy are identical. No significant deviation of cracking between these two temporal loading scenarios can be observed.

2. Cracks in the central part of the loading area are initiated in perpendicular orientation to the surface. The final length of these cracks is dependent on the applied power density. Thus, the length of the crack produced under the triangular loading profile with a steep slope is larger than those of the triangular profile with a gradual slope and of the uniform distribution.

3. Regardless of the thermal loading distribution, cracks produced near the position where the peak stress occurs tend to kink from their initial vertical path at a certain depth (e.g. $0.32 \mathrm{~mm}$ ) and grow further in parallel to the surface.

4. Cracks initiated near the position where the peak stress occurs are more likely to grow further in parallel to the surface under the uniform loading, compared to the triangular loading.

\section{References}

[1] A. Raffray, R. Nygren, D. Whyte, S. Abdel-Khalik, R. Doerner, F. Escourbiac, T. Evans, R. Goldston, D. Hoelzer, S. Konishi, P. Lorenzetto, M. Merola, R. Neu, P. Norajitra, R. Pitts, M. Rieth, M. Roedig, T. Rognlien, S. Suzuki, M. Tillack, C. Wong, Fusion Eng. Des. 85 (2010) 93-108.

[2] M. Merola, L. Plöchl, P. Chappuis, F. Escourbiac, M. Grattarola, I. Smid, R. Tivey, G. Vieider, J. Nucl. Mater. 283-287, Part 2 (2000) 1068 1072.

[3] H. Zohm, Plasma Phys. Controlled Fusion 38 (1996) 105.

[4] T. Hirai, G. Pintsuk, J. Linke, M. Batilliot, J. Nucl. Mater. 390-391 (2009) 751-754.

[5] M. Merola, D. Loesser, A. Martin, P. Chappuis, R. Mitteaua, V. Komarova, R. Pitts, S. Gicquel, V. Barabash, L. Giancarli, J. Palmer, M. Nakahira, A. Loarte, D. Campbell, R. Eaton, A. Kukushkin, M. Sugihara, F. Zhang, C. Kim, R. Raffray, L. Ferrand, D. Yao, S. Sadakov, A. Furmanek, V. Rozov, T. Hirai, F. Escourbiac, T. Jokinen, B. Calcagno, S. Mori, Fusion Eng. Des. 85 (2010) $2312-2322$.

[6] M. Kaufmann, R. Neu, Fusion Eng. Des. 82 (2007) 521 - 527.

[7] J. Roth, K. Schmid, Phys. Scr. T145 (2011) 014031.

[8] B. Riccardi, P. Gavila, R. Giniatulin, V. Kuznetsov, R. Rulev, N. Klimov, D. Kovalenko, V. Barsuk, V. Koidan, S. Korshunov, Fusion Eng. Des. 88 (2013) $1673-1676$.

[9] A. Huber, A. Arakcheev, G. Sergienko, I. Steudel, M. Wirtz, A. V. Burdakov, J. W. Coenen, A. Kreter, J. Linke, P. Mertens, V. Philipps, G. Pintsuk, M. Reinhart, U. Samm, A. Shoshin, B. Schweer, B. Unterberg, M. Zlobinski, Phys. Scr. T159 (2014) 014005.

[10] M. Wirtz, J. Linke, G. Pintsuk, L. Singheiser, M. Zlobinski, J. Nucl. Mater. 438, Supplement (2013) S833 - S836.

[11] I. Garkusha, I. Landman, J. Linke, V. Makhlaj, A. Medvedev, S. Malykhin, S. Peschanyi, G. Pintsuk, A. Pugachev, V. Tereshin, J. Nucl. Mater. 415 (2011) 481-486.

[12] T. Loewenhoff, J. Linke, G. Pintsuk, C. Thomser, Fusion Eng. Des. 87 (2012) $1201-1205$.

[13] G. Pintsuk, T. Loewenhoff, J. Nucl. Mater. 438, Supplement (2013) S945 - S948.

[14] M. Li, E. Werner, J. You, Nucl. Mater. Energy (2014). (Submitted).

[15] Abaqus Analysis User's Manual 6.12., Dassault Systémes Simulia Corp., Providence, RI, USA (2012).

[16] Siemens AG, Internal report on physical parameters of tungsten (1995).

[17] PLANSEE, Tungsten Material Properties and Applications, http://www.plansee.com/en/Materials-Tungsten-403.htm (2014)

[18] P. L. Raffo, J. Less-Common Met. 17 (1969) 133-149.

[19] T. Dümmr, J. C. Lasalvia, G. Ravichandran, M. A. Meyers, Acta Metall. 46 (1998) 6267-6290.

[20] T. Belytschko, T. Black, Int. J. Numer. Meth. Engng 45 (1999) 601-620.

[21] B. Gludovatz, S. Wurster, A. Hoffmann, R. Pippan, Int. J. Refract. Met. Hard Mater. 28 (2010) 674-678.

[22] J. R. Rice, J. Appl. Mech. 35 (1968) 379-386. 